\title{
Long-term effects of vagus nerve stimulation in refractory pediatric epilepsy: A single-center experience
}

\author{
Dilek Yalnizoglu a,*,1, Didem Ardicli a,b,1 ${ }^{\text {a }}$, Burcak Bilginer ${ }^{c}$, Bahadir Konuskan ${ }^{\text {a,d }}$, Kader Karli Oguz ${ }^{\text {e }}$ \\ Nejat Akalan ${ }^{\text {c,f }}$, Güzide Turanli a,g, Serap Saygi ${ }^{\text {h }}$, Meral Topcu ${ }^{\text {a,g }}$ \\ ${ }^{a}$ Hacettepe University Faculty of Medicine, Department of Pediatric Neurology \\ ${ }^{b}$ currently at Health Sciences University Ankara Kecioren Research and Training Hospital \\ c Hacettepe University Faculty of Medicine, Department of Neurosurgery \\ d currently at Mardin State Hospital \\ e Hacettepe University Faculty of Medicine, Department of Neuroradiology \\ ${ }^{\mathrm{f}}$ currently at Medipol University Department of Neurosurgery \\ g currently retired from Hacettepe University, Department of Pediatric Neurology \\ ${ }^{\mathrm{h}}$ Hacettepe University Faculty of Medicine, Department of Neurology
}

\section{A R T I C L E I N F O}

\section{Article history:}

Received 19 February 2020

Accepted 25 April 2020

Available online 27 June 2020

\section{Keywords:}

Vagus nerve stimulation

Drug-resistant epilepsy

Pediatric

\begin{abstract}
A B S T R A C T
Introduction: Vagus nerve stimulation (VNS) has been used as an adjunctive therapy for both children and adults with refractory epilepsy, over the last two decades. In this study, we aimed to evaluate the long-term effects and tolerability of VNS in the pediatric drug-resistant epilepsy (DRE) and to identify the predictive factors for responsiveness to VNS.

Methods: We retrospectively reviewed the medical records of pediatric patients who underwent VNS implantation between 1997 and 2018. Patients with $\geq 50 \%$ reduction of seizure frequency compared with the baseline were defined as "responders". The clinical characteristics of responders and nonresponders were compared. Results: A total of 58 children (male/female: $40 / 18$ ) with a mean follow-up duration of 5.7 years ( 3 months to 20 years) were included. The mean age at implantation was 12.4 years ( 4.5 to 18.5 years). Approximately half (45\%) of our patients were responders, including 3 patients (5.8\%) who achieved seizure freedom during follow-up. The age of seizure-onset, duration of epilepsy, age at implantation, and etiologies of epilepsy showed no significant difference between responders and nonresponders. Responders were more likely to have focal or multifocal epileptiform discharges (63\%) on interictal electroencephalogram (EEG), when compared to nonresponders $(36 \%)(\mathrm{p}=.07)$. Vocal disturbances and paresthesias were the most common side effects, and in two patients, VNS was removed because of local reaction.

Conclusion: Our series had a diverse etiological profile and patients with transition to adult care. Long-term follow-up showed that VNS is an effective and well-tolerated treatment modality for refractory childhood onset epilepsy. Age at implantation, duration of epilepsy and underlying etiology are not found to be predictors of responsiveness to VNS. Higher response rates were observed for a subset of patients with focal epileptiform discharges.
\end{abstract}

(c) 2020 Elsevier Inc. All rights reserved.

\section{Introduction}

Effective treatment of epilepsy is critical in pediatric patients, as uncontrolled seizures may have unfavorable impact on neurodevelopment and quality of life [1,2]. About half of the children with epilepsy respond to the first or second appropriately chosen antiepileptic drug (AED) [3]. About one-third of patients with epilepsy who do not respond to AEDs

\footnotetext{
* Corresponding author at: Hacettepe University Faculty of Medicine, Department of Pediatric Neurology, 06100 Ankara, Turkey.

E-mail address: dileky@hacettepe.edu.tr (D. Yalnizoglu)

1 These authors jointly share first authorship.
}

are considered to have drug-resistant epilepsy (DRE), and only 20$40 \%$ of them are suitable candidates for epilepsy surgery [3,4]. Over the past two decades, vagus nerve stimulation (VNS, Cyberonics ${ }^{\circledR}$ ) has become an accepted treatment modality with a predictable and benign side-effect profile for both pediatric and adult patients with DRE, who are not suitable candidates for epilepsy surgery or have failed surgery [5]. Since 1997, VNS has been approved by the United States Food and Drug Administration (FDA) for $>12$ years children and adults with intractable seizures [6].

Since 2000, the efficacy and safety of VNS in the treatment of DRE have been reported in many studies from different centers. In a metaanalysis of 74 studies, the mean reduction of seizure frequency was 
higher in the pediatric age group (55.3\%) as compared to adults (49.5\%) [7]. In the largest pediatric VNS cohort of 347 children, the response rates at 12 and 24 months of therapy were $38 \%$ and $44 \%$, respectively [2]. Improvement in cognitive functions, verbal communication, memory, attention and concentration has also been reported in many studies $[2,8-10]$. There are limited numbers of studies with long-term outcomes especially more than 10 years follow-up period of VNS therapy in the pediatric age group $[8,11,12]$.

Predictive factors for responsiveness to VNS therapy have also been evaluated in previous studies [4,7,13-15]. Clinical characteristics such as duration of epilepsy, age at implantation, seizure type, etiology, and prior epilepsy surgery have been analyzed as the potential predictive factors.

In this study, we aimed to evaluate the long-term effects and the tolerability of VNS therapy in pediatric patients followed in our center and to compare the clinical characteristics between responders and nonresponders.

\section{Methods}

To analyze the long-term outcomes of VNS therapy in children, we performed a retrospective single-center study including the patients with DRE followed at Hacettepe University Hospitals between June 1997 and December 2018. Patients with a minimum follow-up period of three months were included. The indications for VNS implantation included patients with DRE according to the International League Against Epilepsy (ILAE) criteria and who are not appropriate candidates for epilepsy surgery. A total of 63 pediatric patients with VNS implantation were followed in the study period. Five patients who did not meet the study criteria due to early removal of device because of local reaction $(\mathrm{n}=1)$ or insufficient follow-up data $(\mathrm{n}=4)$ were excluded from the study.

We reviewed the medical data including demographic features, age at seizure-onset, age at implantation, duration of epilepsy prior to implantation, underlying etiologies, number of prior AEDs, history of prior epilepsy surgery, type of predominant seizure, baseline seizure frequency (3 months prior to VNS implantation), history of status epilepticus, follow-up period after implantation, VNS parameters, interictal and ictal video-electroencephalography (EEG) findings, behavioral and cognitive status, side effects, and complications. All of the patients underwent a standardized presurgical evaluation by a multidisciplinary specialized epilepsy team (consisting of pediatric and adult neurologists/epileptologists, neurosurgeons, and neuroradiologists and nuclear medicine physicians, neuropscyhologists). Monitoring with EEG/VideoEEG was performed prior to implantation in all patients. Patients older than 18 years were transferred to adult care at the Department of Neurology. Surgical procedures of implantation have been performed as reported previously [16]. The patients were divided into two groups according to the date of implantation: patients who underwent VNS implantation in the period of 1997-2007 were defined as group 1, and those between 2008 and 2018 were defined group 2 . Analyzes of the patients in two decades were also compared.

The local Ethical Committee of Hacettepe University approved the study.

\subsection{VNS device parameters}

Stimulation parameters were set at standard parameters and were adjusted as required. Rapid cycle was performed for brief periods in selected patients.

\subsection{Clinical assessments and outcomes}

Based on the 2017 ILAE classification [17], etiologies of epilepsy are divided into following groups: structural, metabolic, genetic or presumed genetic, infectious, immune, and unknown. The predominant seizure type was defined as the most frequently observed seizures by parents and the most frequently recorded seizure type during videoEEG. According to the video-EEG findings and reported seizure semiology, the type of predominant seizures was classified as generalized, focal, or unknown. The frequencies of the predominant seizures were evaluated at baseline ( 3 months prior to implantation), at 6 months, 1 , $2,3,4,5$ years post-implantation, and at last visit in available patients. A focal or generalized seizure was defined according to the ILAE criteria [17].

According to the patient's response to VNS at any evaluation time point, patients were divided into two groups: "responder" $(R)$ and "nonresponder" (NR). Patients with $\geq 50 \%$ reduction of predominant seizure frequency compared with the frequency at baseline were defined as "responders", whereas those with $<50 \%$ reduction were defined as "nonresponders". Seizure-free patients and those with $\geq 90 \%$ reduction of seizure frequency were defined as favorable outcome patients.

\subsection{Statistics}

The SPSS version 23 (SPSS Inc., Chicago, IL, USA) was used for the statistical analysis. Student's two-tailed $t$-test was used for comparisons between independent variables with a normal distribution. MannWhitney $U$ test was used for variables showing uneven distribution. Distribution was analyzed by crosstabulation and $\chi 2$ (Pearson, Yates, or Fisher) statistics. A p-value of $<.05$ is considered to be statistically significant.

\section{Results}

\subsection{Study population}

A total of 58 children ( 40 male, 18 female) with a mean age of 12.4 \pm 3.4 years (range $4.5-19$ years) at the time of VNS implantation were included. The mean age of the patients at the time of last visit was $22.13 \pm 7.41$ years (9-39 years). The mean age at seizure-onset and duration of epilepsy were $3.6 \pm 3.1$ years ( 1 month to 11 years) and $8.8 \pm 3.4$ years (2.1-16 years), respectively. The VNS implantation was performed in 24 patients $(41 \%)<12$ years of age and in $34(59 \%)$ $\geq 12$ years of age. The mean follow-up period was $5.7 \pm 4.3$ years ( 3 months-20 years). Baseline characteristics of study population are described in Table 1.

Twenty-seven (47\%) patients underwent VNS implantation in the period of 1997-2007 (Group 1), and 31 (53\%) were implanted between 2008 and 2018 (Group 2). Mean age of implantation and duration of epilepsy prior to implantation were similar between Group 1 (12.5 \pm 3.6 years, $9.4 \pm 3.9$ years $)$ and Group $2(12.3 \pm 3.4$ years, $8.1 \pm$ 2.8 years $)(p=.761$ and $p=.145)$. In terms of seizure type and etiology of epilepsy, there was no statistical difference between two groups ( $\mathrm{p}=$ $.341)$.

\subsection{Etiology for epilepsy}

According to the ILAE classification, 64\% (37/58) of our patients had structural etiology, and 28\% (16/58) had genetic or presumed genetic with an unknown etiology. Perinatal insult ( $\mathrm{n}=17,29 \%)$ and malformations of cortical development $(n=14,22 \%)$ were the most common causes, followed by meningoencephalitis $(n=4,7 \%)$. Nine patients had a history of prior epilepsy surgery including resective surgery in six, and corpus callosotomy in three. History of status epilepticus (SE) was present in 14 (24\%) patients. Among them, one patient (16-yearold girl) with past history of super refractory SE had tried 12 AEDs prior to implantation, and VNS implantation enabled a significant reduction in the number of AEDs. In another patient (13-year-old boy) with multiple SE episodes and history of liver transplantation, VNS was preferred because of limited choice of AEDs. However, the reduction of the seizure frequency after implantation was $<50 \%$ in both. 
Table 1

Baseline clinical characteristics of the patients.

\begin{tabular}{ll}
\hline Variables & \\
\hline Sex, n (\%) & \\
Male & $40(68.9 \%)$ \\
Female & $18(31.1 \%)$ \\
Age at VNS implantation, mean \pm SD (range), years & $12.4 \pm 3.4(4.5-18.5)$ \\
$\quad$ <12 years, n(\%) & $24(41 \%)$ \\
$\geq 12$ years n(\%) & $34(59 \%)$ \\
Duration of follow-up, mean \pm SD (range), years & $5.7 \pm 4.3(3$ mo-20 y) \\
Age at seizure onset, mean \pm SD (range), years & $3.6 \pm 3.1(1 \mathrm{mo}-11$ y) \\
Duration of epilepsy, mean \pm SD (range), years & $8.8 \pm 3.4(2.1-16)$ \\
Etiology of epilepsy n, (\%) & $37(64 \%)$ \\
Structural-metabolic & 17 \\
$\quad$ Perinatal insult & 14 \\
$\quad$ Malformations of cortical development & 3 \\
$\quad$ Brain tumor & 2 \\
Tuberous sclerosis complex & 1 \\
$\quad$ Mesial temporal sclerosis & $4(7 \%)$ \\
Structural-meningoencephalitis & $1(1.5 \%)$ \\
Rasmussen encephalitis & $16(27.5 \%)$ \\
Presumed genetic or unknown & 3 \\
$\quad$ Rett syndrome & 1 \\
GABRA1-related epilepsy & 1 \\
Central incisor syndrome & 11 \\
Unknown (MRI negative) & $14(24 \%)$ \\
History of status epilepticus n, (\%) & $9(15.5 \%)$ \\
History of previous epilepsy surgery & $3.1 \pm 0.9(2-7)$ \\
Number of AEDs prior to implantation, mean \pm SD & \\
(range) & $23(53 \%)$ \\
Predominant seizure type, n (\%) & $20(34.5 \%)$ \\
Focal & $7(12.1 \%)$ \\
Generalized & \\
Unknown & \\
Interictal EEG, n (\%) & \\
Focal/multifocal epileptiform discharges & \\
Generalized epileptiform discharges & \\
\hline
\end{tabular}

\subsection{Seizure type and EEG}

Thirty-one patients (61\%) had focal seizures, and 20 (39\%) patients had generalized seizures as the predominant seizure type. Additionally, 23 patients (47\%) showed focal or multifocal epileptiform discharges, and 27 (53\%) showed generalized epileptiform discharges by interictal EEG.

\subsection{Behavior and cognition}

Majority of the patients had cognitive impairment and behavioral problems at baseline. Data regarding cognitive assessment were available in 45 patients, which included normal $(n=3)$ or borderline ( $n$ $=4)$ intelligence quotient, and mild $(n=11)$, moderate $(n=22)$ and severe $(n=5)$ intellectual disability. The mean number of previously tried AEDs was 8.8 (6-14). Three patients had received ketogenic diet prior to implantation. Eleven patients with severe behavioral problems were on concomitant psychiatric drugs.

\subsection{Outcomes/efficacy}

Among 51 patients with adequate follow-up data, 23 (45.1\%) patients were classified as responders, and 28 (54.9\%) as nonresponders. Percentage of the responders at 6 months, and 1, 2, 3, 4, and 5 years post-implantation were $32.5 \%, 36.9 \%, 48.6 \%, 46.7 \%$, 50\%, and $45.9 \%$, respectively (Fig. 1). Three patients (5.8\%) became seizure-free at 3-year follow-up including one with resolution of electrical status epilepticus in sleep (ESES); underlying etiologies were cortical dysplasia, meningoencephalitis, and perinatal insult, each in one patient. In addition to seizure-free patients, the seizure frequency decreased by $\geq 90 \%$ in 7 (13.7\%) patients. Detailed clinical features of patients who achieved seizure freedom and favorable outcome are shown in Table 2 . All patients who were seizure-free had focal seizures as the predominant seizure type, and two of them showed focal epileptiform discharges on interictal EEG, one had ESES. Among the patients with favorable outcome, focal seizures were predominant in 5/7.

In the nonresponder group, 17 (33\%) patients showed no reduction in the seizure frequency. Two patients experienced an increase in the seizure frequency within the first year of implantation; etiology of epilepsy was unknown in one, and structural (previous tumor surgery) in the other; VNS was discontinued in both patients at 12 and 15 months after implantation.

The age of seizure-onset, duration of epilepsy, age at implantation, and etiologies of epilepsy showed no significant difference between responders and nonresponders (Table 3 ). In the responder group the type of predominant seizure was focal in most (76\%), when compared to the nonresponder group (57\%), but no statistical difference was detected. Responders were more likely to have focal or multifocal epileptiform discharges (63\%) on interictal EEG, when compared to nonresponders (36\%) $(\mathrm{p}=.07)$.

Improvement in overall quality of life mainly in terms of behavior, attention, alertness, mood, and cognitive functions were reported by the parents and patients in $60.4 \%$ (29/48) during follow-up. The mean number of AEDs at last follow-up was not different compared with the baseline (mean 3.1). Five patients underwent epilepsy surgery (corpus callosotomy in 3, and resective surgery in 2) after VNS implantation; two of those patients experienced seizure reduction of $\geq 50 \%$ following surgery. Of note, two patients had surgery after transition to adult care (corpus callosotomy: 1, resective surgery following invasive EEG monitoring: 1$)$.

\subsection{Complications/tolerability}

The vast majority of the patients (\%86) are still receiving VNS therapy. Ten patients underwent second implantation/reoperation during follow-up. The pulse generator was changed because of the battery life ending in 8 patients with an average of 7.3-year time period after implantation. In the remaining two patients, the device was renewed because of technical problems (lead impedance problem) in one, and breakage of the cable during a generalized seizure in the other. The device was removed or discontinued in 8 children because of insufficient efficacy (5), local reaction (2), and broken leads (1). The most common side effects included hoarseness $(n=7)$, coughing $(n=3)$, paresthesia $(\mathrm{n}=4)$, and local pain $(\mathrm{n}=2)$, which were all tolerable and controlled by adjusting the output currents.

\section{Discussion}

Vagus nerve stimulation is a well-tolerated, adjunctive neuromodulatory treatment for DRE with long-term favorable effects

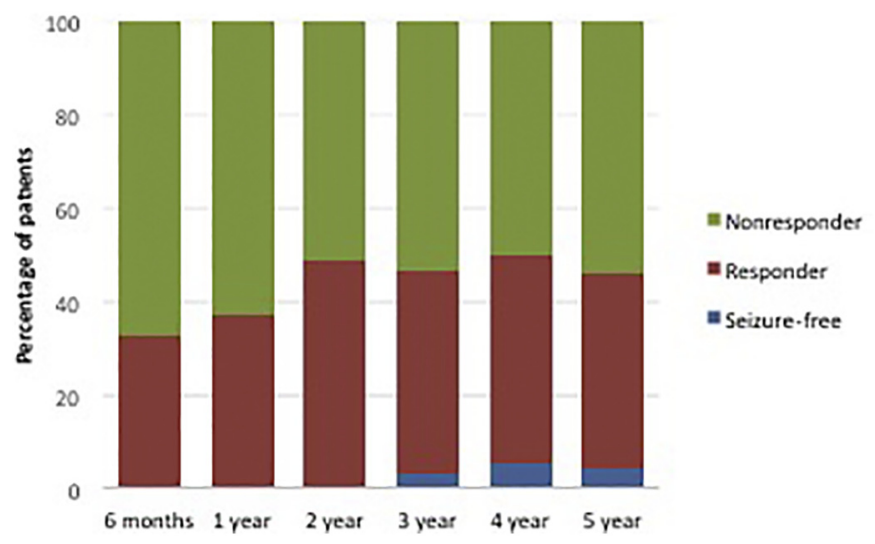

Fig. 1. Changes in the rate of responders/nonresponders during follow-up. 
Table 2

Clinical features of the patients with seizure freedom and favorable outcome.

\begin{tabular}{|c|c|c|c|c|c|c|c|c|}
\hline $\begin{array}{l}\text { Patient } \\
\text { no }\end{array}$ & Sex & $\begin{array}{l}\text { Age at } \\
\text { implantation } \\
\text { (years) }\end{array}$ & $\begin{array}{l}\text { Age at } \\
\text { epilepsy-onset } \\
\text { (months) }\end{array}$ & $\begin{array}{l}\text { Duration of } \\
\text { epilepsy } \\
\text { (months) }\end{array}$ & $\begin{array}{l}\text { Underlying } \\
\text { etiyology }\end{array}$ & $\begin{array}{l}\text { Seizure } \\
\text { type }\end{array}$ & $\begin{array}{l}\text { Interictal } \\
\text { EEG }\end{array}$ & $\begin{array}{l}\text { Final outcome (\% reduction } \\
\text { of } \\
\text { seizures) }\end{array}$ \\
\hline 1 & $\mathrm{~F}$ & 7.2 & 60 & 27 & Rett syndrome & f & f & seizure-free \\
\hline 2 & M & 6.6 & 30 & 49 & HIE & $\mathrm{f}$ & ESES & seizure-free \\
\hline 3 & M & 17 & 84 & 120 & MCD & $\mathrm{f}$ & $\mathrm{f}$ & seizure-free \\
\hline 4 & M & 4.5 & 30 & 25 & $\mathrm{MCD}$ & $\mathrm{f}$ & $\mathrm{g}$ & $\geq \% 90$ \\
\hline 5 & M & 5.4 & 6 & 59 & unknown & $\mathrm{g}$ & $\mathrm{b}$ & $\geq \% 90$ \\
\hline 6 & M & 13.2 & 8 & 151 & HIE & $\mathrm{f}$ & $\mathrm{b}$ & $\geq \% 90$ \\
\hline 7 & $\mathrm{~F}$ & 15.5 & 24 & 162 & tuberosclerosis & $\mathrm{f}$ & $\mathrm{f}$ & $\geq \% 90$ \\
\hline 8 & $\mathrm{~F}$ & 14.3 & 12 & 160 & HIE & $\mathrm{g}$ & $\mathrm{f}$ & $\geq \% 90$ \\
\hline 9 & M & 15 & 36 & 144 & MTS & $\mathrm{f}$ & $\mathrm{f}$ & $\geq \% 90$ \\
\hline 10 & M & 17.5 & 120 & 92 & meningoencephalitis & $\mathrm{f}$ & $\mathrm{f}$ & $\geq \% 90$ \\
\hline
\end{tabular}

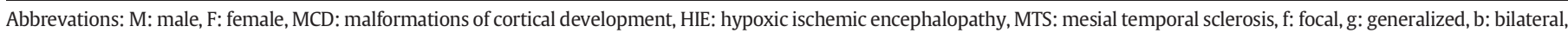
ESES: electrical status epilepticus in sleep.

both in pediatric and adult population. Our results confirm the efficacy and safety of VNS for pediatric DRE in the long-term follow-up (mean $=5.7$ years). Almost half ( $45.1 \%$ ) of our patients had more than $50 \%$ seizure reduction at the last follow-up, including three (5.8\%) patients who reached seizure freedom. Response rates ranged between $35.2-71.3 \%$ in the earlier published pediatric series $[8,10,11]$. In a recent meta-analysis including both pediatric and adult patients, $53.5 \%$ of the patients could achieve $>50 \%$ reduction of seizure frequency after VNS [15]. Another study from Turkey, reporting 56 pediatric patients with a mean follow-up of 87 months demonstrated that $62.5 \%$ of patients were responders at the last follow-up with a higher proportion of (19.6\%) seizure-free patients [18]; VNS appears to be increasingly more effective after several years of exposure. In the current study, a progressive increase in the percentage of responders was observed during the first two years, followed by stabilization of the efficacy over time, consistent with previous literature [2,4]. Gradual increase of efficacy of VNS therapy over time should be taken into consideration when counseling patients and parents.

Various studies have shown that, several clinical features including age at implantation, duration of epilepsy, underlying etiology, seizure type, and interictal EEG findings can be predictive factors for the efficacy of VNS in the pediatric patients [4,7,19-21]. However, predictive factors for efficacy of VNS treatment still seem to be unclear.

Table 3

Comparison of the clinical features between responders and nonresponders.

\begin{tabular}{|c|c|c|c|}
\hline & $\begin{array}{l}\text { Responders } \\
(\mathrm{n}=23,45.1 \%)\end{array}$ & $\begin{array}{l}\text { Nonresponders } \\
(\mathrm{n}=28,54.9 \%)\end{array}$ & $\begin{array}{l}\mathrm{p} \\
\text { value }\end{array}$ \\
\hline \multicolumn{4}{|l|}{ Age at implantation } \\
\hline Mean \pm SD, year & $11.8 \pm 4.2(4.5-18)$ & $\begin{array}{l}12.6 \pm 2.7 \\
(8.1-18.5)\end{array}$ & 0,465 \\
\hline \multicolumn{4}{|l|}{ Age at seizure-onset } \\
\hline Mean \pm SD, year & $\begin{array}{l}3.8 \pm 2.9(2 \mathrm{mo}-10 \\
\mathrm{y})\end{array}$ & $\begin{array}{l}3.9 \pm 2.7(1 \mathrm{mo}-11 \\
\mathrm{y})\end{array}$ & 0,938 \\
\hline \multicolumn{4}{|l|}{ Duration of epilepsy } \\
\hline Mean \pm SD, year & $8.0 \pm 4.1(2.1-16)$ & $8.6 \pm 2.6(4-13.3)$ & 0,513 \\
\hline \multicolumn{4}{|l|}{ Underlying etiology, n (\%) } \\
\hline Structural/metabolic & $17(74 \%)$ & $16(58 \%)$ & \\
\hline Genetic/unknown & $5(22 \%)$ & $10(35 \%)$ & 0.788 \\
\hline Other & $1(4 \%)$ & $2(7 \%)$ & \\
\hline History of SE, n (\%) & $3(13 \%)$ & $4(14 \%)$ & 1.0 \\
\hline Prior epilepsy surgery, n (\%) & $7(30.4 \%)$ & $7(25 \%)$ & 0.665 \\
\hline \multicolumn{4}{|c|}{$\begin{array}{l}\text { Predominant seizure type, } \mathrm{n} \\
\text { (\%) }\end{array}$} \\
\hline Focal & $16(69.6 \%)$ & $15(53.6 \%)$ & 0.377 \\
\hline Generalized & $5(21.7 \%)$ & $11(39.3 \%)$ & \\
\hline Unknown & $2(11.8 \% \%)$ & $2(7.1 \%)$ & \\
\hline \multicolumn{4}{|l|}{$\begin{array}{l}\text { Interictal EEG findings, } \mathrm{n} \\
(\%)\end{array}$} \\
\hline Focal/multifocal & $12(63.2 \%)$ & $9(36 \%)$ & $0.074^{*}$ \\
\hline Generalized & $7(36.8 \%)$ & $16(64 \%)$ & \\
\hline
\end{tabular}

The mean age of implantation was 12.4 years and the youngest patient was implanted at the age of 4.5 years in our study. Comparisons between the age of implantation $\geq 12$ years and those $<12$ years of age showed no differences in terms of response rates. Several studies have demonstrated that younger age at implantation lead to better outcome $[2,13,22-24]$. In a cohort of 70 pediatric patients, younger age at implantation ( $<5$ years) showed better outcome with the response rate of $77 \%$, as compared with the older age group ( $>15$ years) where the response rate was 37\% [23]. However, in a recent meta-analysis of 14 studies, age at VNS implantation as a predictor for outcome showed no significant difference between responders and nonresponders [15].

Duration of epilepsy is considered to be another significant predicting factor for seizure outcome. In the current study, epilepsy duration did not show a significant difference between responders and nonresponders. Similar to our findings, longer duration of epilepsy did not predict worse seizure reduction outcome in several studies. By contrast, Colicchio et al. and Arya et al. reported that a shorter duration of epilepsy before VNS implantation was a predictive factor associated with good outcome $[13,19]$.

Underlying etiologies of epilepsy have also been evaluated in many studies to predict responsiveness to VNS therapy. Arya et al. suggested that nonlesional patients would be good responders for VNS, similar to the study of Elliot et al. $[4,19]$. However, Landi et al. and Colicchio et al. found that structural epilepsies responded better when compared to genetic epilepsies or those with unknown etiology [13]. Englot et al. showed that patients with posttraumatic epilepsy or tuberous sclerosis achieved a significantly better outcome after VNS [7]. In a cohort of 144 patients that included 63 children, cortical dysgenesis showed a better response to VNS by multivariate analysis [20]. Our patients had a diverse etiological profile, and seizure outcome was not associated with the underlying etiology. However, in the subgroup of our patients with favorable outcome ( $\geq 90 \%$ reduction of seizure frequency), etiology of epilepsy was structural in most (80\%).

Seizure type and interictal EEG findings are other potential predictors of responsiveness to VNS. Two previous large pediatric series reported that both generalized and focal seizures showed good responses to VNS $[2,4]$. Recently, Kim et al. evaluated 58 children with DRE and suggested that focal seizures and focal or multifocal epileptiform discharges on interictal EEG were significantly associated with a good response to VNS therapy [14]. Similarly, Ghaemi et al. reported that unilateral interictal epileptiform discharges were independent predictors of good response to VNS in the long-term follow-up [20]. Although no statistical difference was detected in the present study, the responders were more likely to have focal seizures when compared with the nonresponders (76\% versus 57\%) and focal or multifocal epileptiform discharges (63\%) on interictal EEG (63\% versus $36 \%, \mathrm{p}=.07$ ).

When we compared the patients according to the time of VNS implantation, the age of VNS implantation, duration of epilepsy, seizure type and etiology of epilepsy, there was no significant difference 
between Group 1 and Group 2, representing two decades. Despite increasing experience with VNS and introduction of new generation AEDs over time, timing of VNS implantation and patient profile remained similar; which may be resulting from late referral for epilepsy surgery in general.

Our patients had tried a mean of 8.2 AEDs prior to implantation, and the mean number of the AEDs (mean $=3.1$ ) remained stable during follow-up, which is also consistent with the published data [2,25]. In our study, only three patients had ketogenic diet prior to implantation, which was lower than other series in the literature. We consider this finding as underutilization of ketogenic diet at the time of study onset in Turkey.

Beneficial effects of VNS on behavioral outcomes and quality of life in children have also been reported in several studies [9,12,26-28]. Based on the available patient/parent records improvement in the quality of life was observed in more than half of our patients $(60 \%)$, even in the nonresponder group. This may be due to the direct effect of VNS on behavior and alertness, as well as having less severe seizures or fewer episodes of status epilepticus.

Vagus nerve stimulation therapy has proven to be safe and well tolerated in both pediatric and adult patients. In the current study, the majority of side effects were mild and adjusted by stimulus modifications. The complication rate in our cohort was similar to previous publications $[2,7]$. Complications associated with implantation have included local reaction $(n=2)$, and lead impedance problem $(n=1)$.

The major limitations of our study are relatively small sample size, limiting the statistical power and retrospective collection of the data. Accurate determination of seizure frequency was also difficult and based on the information reported by patients and families. Although all of the patients in our study underwent VNS implantation in childhood, about $60 \%$ are currently adult patients; merely half of them remain at follow-up. Of note 5 patients underwent epilepsy surgery following VNS, two of them as adult patients. Transition to adult care is critical for patients with DRE and VNS implantation who require long-term follow-up. Despite limitations mentioned above, we have demonstrated the efficacy and safety of VNS in a large group of pediatric patients with a long-term follow-up.

\section{Conclusion}

The results of the current study are consistent with the earlier reports that seizure reduction showed time dependence. Age at seizure onset, age at implantation, and duration of epilepsy are not found to be predictors of seizure reduction outcome after VNS implantation. Our patients had a diverse etiological profile, and seizure outcome was not related to the underlying etiology. Vagus nerve stimulation appears to be effective for different types of epilepsy regardless of the underlying etiology. Higher response rates were observed for a subset of patients who have focal or multifocal epileptiform discharges.

\section{Declaration of competing interest}

The authors have declared that no conflict of interest exits.

\section{Acknowledgments}

We thank referring physicians, pediatric and adult neurologists/ epileptologists, neurosurgeons who took care of our patients at Hacettepe University Hospitals and outside hospitals.

\section{References}

[1] Kwan P, Brodie MJ. Early identification of refractory epilepsy. N Engl J Med. 2000; 342:314-9.

[2] Orosz I, McCormick D, Zamponi N, Varadkar S, Feucht M, Parain D, et al. Vagus nerve stimulation for drug-resistant epilepsy: a European long-term study up to 24 months in 347 children. Epilepsia. 2014;55:1576-84.
[3] Kwan P, Arzimanoglou A, Berg AT, Brodie MJ, Allen Hauser W, Mathern G, et al. Definition of drug resistant epilepsy: consensus proposal by the ad hoc task force of the ILAE commission on therapeutic strategies. Epilepsia. 2010; 51:1069-77.

[4] Elliott RE, Morsi A, Kalhorn SP, Marcus J, Sellin J, Kang M, et al. Vagus nerve stimulation in 436 consecutive patients with treatment-resistant epilepsy: long-term outcomes and predictors of response. Epilepsy Behav. 2011;20:57-63.

[5] Morris 3rd GL, Gloss D, Buchhalter J, Mack KJ, Nickels K, Harden C. Evidence-based guideline update: vagus nerve stimulation for the treatment of epilepsy: report of the guideline development Subcommittee of the American Academy of Neurology. Neurology. 2013;81:1453-9.

[6] Handforth A, DeGiorgio CM, Schachter SC, Uthman BM, Naritoku DK, Tecoma ES, et al. Vagus nerve stimulation therapy for partial-onset seizures: a randomized active-control trial. Neurology. 1998;51:48-55.

[7] Englot DJ, Chang EF, Auguste KI. Vagus nerve stimulation for epilepsy: a metaanalysis of efficacy and predictors of response. J Neurosurg. 2011;115: 1248-55.

[8] Elliott RE, Morsi A, Tanweer O, Grobelny B, Geller E, Carlson C, et al. Efficacy of vagus nerve stimulation over time: review of 65 consecutive patients with treatmentresistant epilepsy treated with VNS > 10 years. Epilepsy Behav. 2011;20:478-83.

[9] Terra VC, Furlanetti LL, Nunes AA, Thome U, Nisyiama MA, Sakamoto AC, et al. Vagus nerve stimulation in pediatric patients: is it really worthwhile? Epilepsy Behav. 2014;31:329-33.

[10] Helmers SL, Wheless JW, Frost M, Gates J, Levisohn P, Tardo C, et al. Vagus nerve stimulation therapy in pediatric patients with refractory epilepsy: retrospective study. J Child Neurol. 2001;16:843-8.

[11] Galbarriatu L, Pomposo I, Aurrecoechea J, Marinas A, Agundez M, Gomez JC, et al. Vagus nerve stimulation therapy for treatment-resistant epilepsy: a 15-year experience at a single institution. Clin Neurol Neurosurg. 2015;137:89-93.

[12] Wasade VS, Schultz L, Mohanarangan K, Gaddam A, Schwalb JM, Spanaki-Varelas M. Long-term seizure and psychosocial outcomes of vagus nerve stimulation for intractable epilepsy. Epilepsy Behav. 2015;53:31-6.

[13] Colicchio G, Policicchio D, Barbati G, Cesaroni E, Fuggetta F, Meglio M, et al. Vagal nerve stimulation for drug-resistant epilepsies in different age, aetiology and duration. Childs Nerv Syst. 2010;26:811-9.

[14] Kim MJ, Yum MS, Kim EH, Lee YJ, Lee J, Hong S, et al. An interictal EEG can predict the outcome of vagus nerve stimulation therapy for children with intractable epilepsy. Childs Nerv Syst. 2017;33:145-51

[15] Wang HJ, Tan G, Zhu LN, Chen D, Xu D, Chu SS, et al. Predictors of seizure reduction outcome after vagus nerve stimulation in drug-resistant epilepsy. Seizure. 2019;66: 53-60.

[16] Hauptman JS, Mathern GW. Vagal nerve stimulation for pharmacoresistant epilepsy in children. Surg Neurol Int. 2012;3:S269-74.

[17] Scheffer IE, Berkovic S, Capovilla G, Connolly MB, French J, Guilhoto L, et al. ILAE classification of the epilepsies: position paper of the ILAE Commission for Classification and Terminology. Epilepsia. 2017;58:512-21.

[18] Serdaroglu A, Arhan E, Kurt G, Erdem A, Hirfanoglu T, Aydin K, et al. Long term effect of vagus nerve stimulation in pediatric intractable epilepsy: an extended follow-up. Childs Nerv Syst. 2016;32:641-6.

[19] Arya R, Greiner HM, Lewis A, Horn PS, Mangano FT, Gonsalves C, et al. Predictors of response to vagus nerve stimulation in childhood-onset medically refractory epilepsy. J Child Neurol. 2014;29:1652-9.

[20] Ghaemi K, Elsharkawy AE, Schulz R, Hoppe M, Polster T, Pannek H, et al. Vagus nerve stimulation: outcome and predictors of seizure freedom in long-term follow-up. Seizure. 2010;19:264-8.

[21] Janszky J, Hoppe M, Behne F, Tuxhorn I, Pannek HW, Ebner A. Vagus nerve stimulation: predictors of seizure freedom. J Neurol Neurosurg Psychiatry. 2005;76:384-9.

[22] Alexopoulos AV, Kotagal P, Loddenkemper T, Hammel J, Bingaman WE. Long-term results with vagus nerve stimulation in children with pharmacoresistant epilepsy. Seizure. 2006;15:491-503.

[23] Lagae L, Verstrepen A, Nada A, Van Loon J, Theys T, Ceulemans B, et al. Vagus nerve stimulation in children with drug-resistant epilepsy: age at implantation and shorter duration of epilepsy as predictors of better efficacy? Epileptic Disord. 2015;17: 308-14.

[24] Soleman J, Knorr C, Datta AN, Strozzi S, Ramelli GP, Mariani L, et al. Early vagal nerve stimulator implantation in children: personal experience and review of the literature. Childs Nerv Syst. 2018;34:893-900.

[25] Bodin E, Le Moing AG, Bourel-Ponchel E, Querne L, Toussaint P, Berquin P. Vagus nerve stimulation in the treatment of drug-resistant epilepsy in 29 children. Eur J Paediatr Neurol. 2016;20:346-51.

[26] Kawai K, Tanaka T, Baba H, Bunker M, Ikeda A, Inoue Y, et al. Outcome of vagus nerve stimulation for drug-resistant epilepsy: the first three years of a prospective Japanese registry. Epileptic Disord. 2017;19:327-38.

[27] Klinkenberg S, van den Bosch CN, Majoie HJ, Aalbers MW, Leenen L, Hendriksen J, et al. Behavioural and cognitive effects during vagus nerve stimulation in children with intractable epilepsy - a randomized controlled trial. Eur J Paediatr Neurol. 2013;17:82-90.

[28] Helmers SL, Duh MS, Guerin A, Sarda SP, Samuelson TM, Bunker MT, et al. Clinical outcomes, quality of life, and costs associated with implantation of vagus nerve stimulation therapy in pediatric patients with drug-resistant epilepsy. Eur J Paediatr Neurol. 2012;16:449-58. 